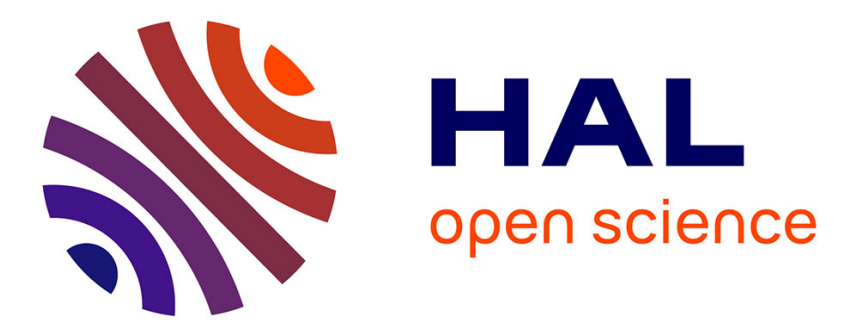

\title{
Morphological effects on catalytic performance of LTL zeolites in acylation of 2-methylfuran enhanced by non-microwave instant heating
}

\author{
Nur Hidayahni Ahmad, T. Jean Daou, Pedro Maireles-Torres, Moussa \\ Zaarour, Svetlana Mintova, Tau-Chuan Ling, Eng-Poh Ng
}

\section{To cite this version:}

Nur Hidayahni Ahmad, T. Jean Daou, Pedro Maireles-Torres, Moussa Zaarour, Svetlana Mintova, et al.. Morphological effects on catalytic performance of LTL zeolites in acylation of 2-methylfuran enhanced by non-microwave instant heating. Materials Chemistry and Physics, 2020, 244, pp.122688. 10.1016/j.matchemphys.2020.122688 . hal-02893849

\section{HAL Id: hal-02893849 \\ https://hal.science/hal-02893849}

Submitted on 26 Nov 2020

HAL is a multi-disciplinary open access archive for the deposit and dissemination of scientific research documents, whether they are published or not. The documents may come from teaching and research institutions in France or abroad, or from public or private research centers.
L'archive ouverte pluridisciplinaire HAL, est destinée au dépôt et à la diffusion de documents scientifiques de niveau recherche, publiés ou non, émanant des établissements d'enseignement et de recherche français ou étrangers, des laboratoires publics ou privés. 


\title{
Morphological Effects on Catalytic Performance of LTL Zeolites in Acylation of 2-Methylfuran Enhanced by Non-Microwave Instant Heating
}

Nur Hidayahni Ahmad, ${ }^{\mathrm{a}}$ T. Jean Daou, ${ }^{\mathrm{b}, \mathrm{c}}$ Pedro Maireles-Torres, ${ }^{\mathrm{d}}$ Moussa Zaarour, ${ }^{\mathrm{e}}$ Svetlana Mintova, ${ }^{\text {eff }}$ Tau-Chuan Ling, ${ }^{\mathrm{g}}$ Eng-Poh $\mathrm{Ng}^{\mathrm{a}}{ }^{*}$

${ }^{a}$ School of Chemical Sciences, Universiti Sains Malaysia, 11800 USM, Penang, Malaysia.

${ }^{b}$ Université de Haute-Alsace, Axe Matériaux à Porosités Contrôlées, Institut de Science de Matériaux de Mulhouse UMR 7361, ENSCMu, $3 b$ rue Alfred Werner, 68093 Mulhouse, France.

${ }^{c}$ Université de Strasbourg, 67000 Strasbourg, France.

${ }^{d}$ Departamento de Quimica Inorganica Cristalografia y Mineralogia (Unidad Asociada al ICP-CSIC) Facultad de Ciencias Campus de Teatinos, Universidad de Mlaga, 29071 Malaga, Spain.

${ }^{e}$ Laboratoire Catalyse \& Spectrochimie, ENSICAEN, Université de Caen, 14000 Caen, France.

${ }^{f}$ State Key Laboratory of Heavy Oil Processing, College of Chemical Engineering, China University of Petroleum (East China), Qingdao, 266580, China.

${ }^{g}$ Institute of Biological Sciences, Faculty of Science, University of Malaya, 50603 Kuala Lumpur, Malaysia.

*Corresponding author. E-mail address: epng@usm.my

\begin{abstract}
Morphological characteristics of zeolites can have significant effects on the catalytic reactions. However, the roles of zeolite morphology on catalytic reactions, particularly Friedel-Crafts acylation of 2-methylfuran, are still not clear. Hence, LTL-type zeolites with different
\end{abstract}


morphologies are prepared by using bamboo leaf bio-silica source where the zeolites are used to elucidate the morphological properties in this acylation reaction. The results show that LTL zeolites with short-rod, cylindrical, stick-like and nanosized shapes can be prepared by simply tuning the water content of the precursor hydrogels and the crystallization time. The morphological properties of LTL zeolites are also found to have pronounced influences on their surface properties (surface areas, pore volumes, number of micropore channels, textural properties) and acidity (amount, strength and type) where these properties affect their catalytic activity in acylation of 2-methylfuran under non-microwave instant heating condition. Furthermore, the influence of temperature and heating time on the kinetics of catalytic acylation of 2-methylfuran, and the catalytic comparative study between nanosized LTL zeolite and several homogeneous and heterogeneous catalysts are also discussed.

Keywords: LTL zeolite; bamboo leaves ash; morphology; acylation of 2-methylfuran; nonmicrowave instant heating

\section{Introduction}

The upgrading of renewable feedstock is paramount for its conversion into more valuable fuels and chemicals, and hence central to the field of petrochemical research [1]. Among these compounds, furfurals (e.g. furfural (FAL) and 5-hydroxymethylfurfural (HMF)) have been identified as very useful compounds for the production of value-added intermediates and bio-fuels [2-4]. Upgrading of furans to higher-value added products and fuel additives can be achieved through different approaches such as Friedel-Crafts, hydrogenation, etherification, hydrogenolysis, etc. [5-9]. Particularly, acylation of 2-methylfuran produces 2-acetyl-5methylfuran, viz. a valuable biofuel and intermediate in pharmaceutical industry [10]. 
Most of the Friedel-Crafts acylation reactions is driven by catalysts with high acidity such as $\mathrm{H}_{2} \mathrm{SO}_{4}, \mathrm{HF}, \mathrm{AlCl}_{3}$ and $\mathrm{FeCl}_{3}$ [11]. However, these homogenous catalysts are harmful, corrosive, less selective and difficult to handle. The design of cheaper, less toxic, less corrosive and reusable heterogeneous solid catalysts (zeolites [12-16], metal organic frameworks [17], clays [18], mesoporous silicas [19, 20]) for the efficient catalyzing acylation reaction is a green chemistry approach. In particular, zeolites-the ordered microporous aluminosilicate minerals - have found dominating the catalyst global market [21].

The use of zeolites for catalyzing the Friedel-Crafts acylation of 2-methylfuran has been experimentally demonstrated by two research groups thus far [22, 23]. Xiong et al. modified $\mathrm{H}-\beta$ zeolite using acid treatment with acetic and tartaric acids [22]. They found that the activity of zeolite in acylation of 2-methyfuran with acetic anhydride was mainly connected with the Brönsted acid sites and their acid strength. Gumidyala et al. studied the effects of pore size of H-ZSM-5 and H- $\beta$ zeolites on the catalytic acylation of 2-methylfuran with acetic acid [23]. H-ZSM-5 zeolite with smaller pore size exhibited a higher turnover frequency (TOF) and improved catalyst stability than large-pore $\mathrm{H}-\beta$ zeolite where pore confinement played a crucial role in this reaction. Furthermore, their DFT calculation also showed that the acyl formation was a limiting step in the overall reaction rate.

Meanwhile, Zhang and co-workers also used DFT electronic structure calculation to study the acylation of 2-methylfuran with acetic anhydride catalyzed by $\mathrm{H}-\beta$ (Brönsted-acidic) and Sn- $\beta$ (Lewis-acidic) zeolites [10]. They found that this reaction underwent different catalytic pathways whereby dissociation of the C-O-C linkage of the anhydride to acylium cation (by H- $\beta$ ) and acetoxy anion (by Sn- $\beta$ ) controlled the formation of 2-acetyl-5-methylfuran while hydrogen elimination was the rate-determining step in this coupling reaction.

Morphological properties play a crucial rule in many catalytic reactions as they provide different diffusion pathways and catalytic activity [24, 25]. However, the roles of zeolite 
morphology on Friedel-Crafts acylation of 2-methylfuran are still not clear and hence any effort to elucidate these properties of zeolites in this reaction is urgently needed. The present work is mainly aimed on the use of new bio-silica source from bamboo leaves to synthesize LTL zeolites with different morphologies (short-rod, cylindrical, stick-like and nanosized shapes). LTL zeolite is chosen in this study for morphological effect study on catalytic acylation of 2methylfuran because its morphology is easy to control by simply changing the water content in the precursor hydrogel and heating temperature [26]. In addition, the synthesis of LTL zeolite using bamboo leaf ash (BLA) is also interesting because bamboo leaves are renewable, easy to cultivate, abundance in Asia and have very high natural silica content (20-41\%) [27].

\section{Experimental}

\subsection{Preparation of bamboo leaf ash (BLA)}

Bamboo leaves (45.00 g) were first washed thoroughly with water, dried and blended into small pieces. The dried leaves were then treated with nitric acid (1.0 M, 1.0 L, Merck) under shaking $(100 \mathrm{rpm})$ at room temperature for $16 \mathrm{~h}$ to remove unwanted inorganic impurities. The leached leaves were filtered and washed thoroughly with distilled water until the $\mathrm{pH}$ reached 7 . The acid treated leaves were dried overnight at $60{ }^{\circ} \mathrm{C}$ before subjecting to combustion at $600{ }^{\circ} \mathrm{C}$ in air for $6 \mathrm{~h}$ with a heating rate of $2.0^{\circ} \mathrm{C} / \mathrm{min}$. Pure white BLA $(33.1 \%$ inorganic solid yield was calculated based on dried leaves with $98.5 \%$ of $\mathrm{SiO}_{2}$ ) was obtained as the final product. Trace amount of other metal oxides in the BLA was also detected, such as $\mathrm{P}_{2} \mathrm{O}_{5}: 0.70 \%, \mathrm{CaO}: 0.19 \%, \mathrm{Al}_{2} \mathrm{O}_{3}: 0.16 \%, \mathrm{Fe}_{2} \mathrm{O}_{3}: 0.11 \%, \mathrm{MgO}: 0.11 \%, \mathrm{Na}_{2} \mathrm{O}: 0.10 \%, \mathrm{~K}_{2} \mathrm{O}:$ 0.08\%, MnO: $0.03 \%$.

\subsection{Hydrothermal synthesis of LTL zeolites}


LTL zeolite with nanosized morphology was synthesized by first stirring BLA (5.083 $\mathrm{g})$ in a solution containing distilled water $(17.280 \mathrm{~g})$ and $\mathrm{KOH}\left(5.501 \mathrm{~g}, 85 \%\right.$, Merck) at $90{ }^{\circ} \mathrm{C}$ for $2 \mathrm{~h}$. An aluminate solution was also prepared by mixing $\mathrm{Al}_{2}\left(\mathrm{SO}_{4}\right)_{3} \cdot 16 \mathrm{H}_{2} \mathrm{O}(2.708 \mathrm{~g}, 97 \%$, BDH Chemical Ltd) with distilled water $(11.520 \mathrm{~g})$ at room temperature where a slightly cloudy solution was obtained. The clear silicate solution was then added dropwise to the aluminate solution under vigorous stirring in order to produce a hydrogel with a final molar composition of $10.0 \mathrm{~K}_{2} \mathrm{O}: 1 \mathrm{Al}_{2} \mathrm{O}_{3}: 20 \mathrm{SiO}_{2}: 400 \mathrm{H}_{2} \mathrm{O}$. The resulting hydrogel was further aged under stirring at room temperature for additional $24 \mathrm{~h}$ before subjecting to hydrothermal heating at $180{ }^{\circ} \mathrm{C}$ for $5 \mathrm{~h}$. The white solid product was centrifuged ( $\left.10000 \mathrm{rpm}, 20 \mathrm{~min}\right)$, washed with distilled water until $\mathrm{pH} 7$ and freeze-dried. The LTL zeolites with other morphologies (short-rod, cylindrical and stick-like shapes) were also prepared using similar mixing and crystallization procedures but with different hydrogel molar compositions and heating time (Table 1).

To prepare protonated form of LTL zeolite, the as-synthesized LTL zeolite (3.000 $\mathrm{g}$ ) was ion-exchanged in a $\mathrm{NH}_{4} \mathrm{NO}_{3}$ solution $(1.5 \mathrm{M}, 100 \mathrm{~mL}$, Merck) at room temperature for 18 $\mathrm{h}$ before it was subjected to calcination $\left(480{ }^{\circ} \mathrm{C}, 4 \mathrm{~h}\right)$. For nanosized LTL zeolite, the protonation was performed using multiple ion exchange process with Amberlite ${ }^{\circledR}$ IR 120 resin (Sigma-Aldrich) at room temperature.

\subsection{Characterizations of LTL zeolites}

The XRD diffractograms were recorded using a Bruker-AXS D8 diffractometer with a scan speed of $0.2^{\circ} / \mathrm{min}$ and a step size of $0.02^{\circ}\left(\mathrm{CuK}_{\alpha}\right.$ radiation, $\lambda=0.15418 \mathrm{~nm}, 40 \mathrm{kV}$ and 10 $\mathrm{mA}$ ). The surface and morphological properties of samples were studied with a JEOL JSM6701F FESEM microscope. The average dimensions (length and width) of zeolite crystals were determined using ImageJ software based on 50 particles through SEM or TEM images obtained 
at different spots. The chemical composition ( $\mathrm{Si} / \mathrm{Al}$ ratio) for each sample was acquired using an Optima 8300 inductively coupled plasma-optical emission spectrometer (ICP-OES). Prior to measurement, the zeolite solid $(0.025 \mathrm{~g})$ was first dissolved in a hydrofluoric acid solution containing $0.575 \mathrm{~g}$ hydrofluoric acid $48 \%$ and $24.701 \mathrm{~g} \mathrm{H}_{2} \mathrm{O}$ while boric acid $(0.700 \mathrm{~g})$ was also added to minimize the fluoride interferences. The porous properties of the samples were studied by using a Micrometrics ASAP 2010 nitrogen adsorption analyzer at $-196{ }^{\circ} \mathrm{C}$. The zeolite powder (ca. $80 \mathrm{mg}$ ) was first dehydrated at $300{ }^{\circ} \mathrm{C}$ under vacuum for $15 \mathrm{~h}$ prior to $\mathrm{N}_{2}$ adsorption. The total surface area $\left(\mathrm{S}_{\mathrm{BET}}\right)$ and pore size distribution of each sample were estimated by applying the Brunauer-Emmett-Teller (BET) and Density Functional Theory (DFT) methods, respectively. The micropore $\left(\mathrm{S}_{\text {micro }}\right)$ and external $\left(\mathrm{S}_{\mathrm{ext}}\right)$ surface areas were determined by using the $t$-plot method. The total pore volume $\left(\mathrm{V}_{\text {Total }}\right)$ of the samples was calculated at $\mathrm{P} / \mathrm{P}_{\mathrm{o}}=0.990$. The thermogravimetry analysis was carried out with a Mettler TGASDTA851 analyzer using a heating rate of $20{ }^{\circ} \mathrm{C} \mathrm{min}^{-1}$ and air flow condition. The functional groups and structural stability of zeolite samples were investigated with a Perkin Elmer's System 2000 IR spectrometer $\left(4 \mathrm{~cm}^{-1}, 50\right.$ scans, $\left.400-4000 \mathrm{~cm}^{-1}\right)$ where the transparent pellets were prepared by using the $\mathrm{KBr}$ pellet method $(\mathrm{KBr}$ :sample ratio $=50: 1)$. The nature of acid sites of samples was studied by using pyridine adsorption coupled with infrared spectroscopy. Typically, a self-supporting wafer (ca. $10 \mathrm{mg}$, area $2 \mathrm{~cm}^{2}$ ) was placed into an IR vacuum cell and activated at $400{ }^{\circ} \mathrm{C}$ under vacuum $\left(10^{-3}\right.$ mbar $)$ for $5 \mathrm{~h}$. The background spectrum of zeolite was recorded after cooling. Pyridine vapor was then introduced into the cell for 3 min to allow pyridine adsorption to take place. The excess pyridine vapor was evacuated and the IR spectrum was recorded $\left(6 \mathrm{~cm}^{-1}\right.$ resolution, 200 scans). The sample was heated again for $1 \mathrm{~h}$ at $150{ }^{\circ} \mathrm{C}$ and the second IR spectrum was acquired after cooling to $25^{\circ} \mathrm{C}$. The desorption temperature was raised again to the desired temperatures $\left(150{ }^{\circ} \mathrm{C}\right.$ and $\left.300{ }^{\circ} \mathrm{C}\right)$ and heated for $1 \mathrm{~h}$ before the subsequent spectra were collected upon cooling. The 
concentration of Lewis and Brönsted acid sites of each sample were computed according to ref. [28].

\section{$2.4 \quad$ Catalytic testing}

The catalytic acylation reaction of 2-methylfuran with acetic anhydride was studied using non-microwave instant heating technique. First, the activated zeolite $\left(0.300 \mathrm{~g}, 400{ }^{\circ} \mathrm{C}, 4\right.$ h), 2-methylfuran (4.7 mmol, 99\%, Merck) and acetic anhydride (14.1 mmol, 98.5\%, Merck) were added into a $10-\mathrm{mL}$ glass reaction vial. The vial was sealed and inserted into a nonmicrowave instant heating reactor (Monowave 50, Anton Paar). The reactants were magnetically stirred $(800 \mathrm{rpm})$ and the reaction temperature was set to the desired temperature using "as fast as possible" mode of heating where this mode only took less than 2 min to reach the setting temperature; the reaction temperature from 140 to $160{ }^{\circ} \mathrm{C}$ was chosen because acylation of 2-methylfuran studied at this temperature range is the most ideal where the conversion and reaction kinetics can be easily followed within short time period especially in the presence of acidic zeolite catalyst. The reaction vial was immediately cooled down before the reaction solution was injected into a gas chromatograph (Agilent 7890A, Equity-5 capillary column) where toluene was used as an internal standard. In addition, a gas chromatographmass spectrometer (Agilent 7000 Series Triple Quad) was also used to identify the reaction product. The reaction conversion and the selectivity of 2-acetyl-5-methylfuran were calculated by using the following equations:

$$
\begin{gathered}
\text { \% Conversion }=\left[\frac{\left(\frac{\mathrm{A}_{2-\text { methylfuran }}}{\mathrm{A}_{\text {toluene }}}\right)_{\mathrm{t}_{0}}-\left(\frac{\mathrm{A}_{2-\text { methylfuran }}}{\mathrm{A}_{\text {toluene }}}\right)_{\mathrm{t}_{\mathrm{i}}}}{\left(\frac{\mathrm{A}_{2-\text { methylfuran }}}{\mathrm{A}_{\text {toluene }}}\right)_{\mathrm{t}_{0}}}\right] \times 100 \% \quad \text { (Equation 1) } \\
\text { \% Selectivity }=\frac{\mathrm{A}_{2 \text {-acetyl-5-methylfuran }}}{\mathrm{A}_{\text {total }}} \times 100 \%
\end{gathered}
$$


where $A_{2 \text {-methylfuran }}=$ Peak area of 2-methylfuran, $A_{\text {toluene }}=$ Peak area of toluene, $t_{0}=$ reaction time at $0 \mathrm{~h}, \mathrm{t}_{\mathrm{i}}=$ reaction time at $\mathrm{i}, \mathrm{A}_{2 \text {-acetyl-5-methylfuran }}=$ Peak area of 2-acetyl-5-methylfuran, and $A_{\text {total }}=$ Peak area of product peaks. The catalytic reaction was repeated twice and the results were reported as average \pm standard deviation.

\subsection{Effects of catalytic reaction parameters and catalyst reusability studies}

The effects of reaction parameters, such as reaction temperature $\left(140-160{ }^{\circ} \mathrm{C}\right)$, heating time (5-40 min) and type of catalysts (glacial acetic acid, nitric acid, sulfuric acid, $\mathrm{ZnCl}_{2}$, $\mathrm{FeCl}_{3}, \mathrm{H}-\mathrm{Y}, \mathrm{H}-\mathrm{MCM}-41$ and $\mathrm{AlF}_{2.9}(\mathrm{OH})_{0.1}$ where $0.1148 \mathrm{mmol}$ of liquid or solid catalyst equivalent to $0.30 \mathrm{~g}$ zeolite LTL was used) were also studied using the same procedure reported in Section 2.4. For catalyst reusability study, the catalyst after the first reaction at intermediate conversion level (ca. $50 \%, 160{ }^{\circ} \mathrm{C}, 1 \mathrm{~min}$ ) was separated and washed with diethyl ether twice. The solid was air dried and re-activated $\left(400^{\circ} \mathrm{C}, 4 \mathrm{~h}\right)$ again before being used for the subsequent cycles of catalytic reaction using the same reaction condition.

\section{Results and discussion}

\subsection{Characterization of LTL zeolites}

LTL zeolite is a large-pore molecular sieve having an one-dimensional channel system with cylindrical shape. The unique morphology and pore opening $\left(7.5 \times 7.5 \AA^{2}\right)$ of LTL zeolite are desirable in this work since it allows 2-methylfuran $\left(4.89 \times 4.25 \times 1.80 \AA^{3}\right)$ and acetic anhydride $\left(5.89 \times 3.30 \times 1.81 \AA^{3}\right)$ to diffuse easily into the pores and further react on the acid sites of the zeolite (Fig. 1) [29, 30]. Furthermore, the appropriate pore size of LTL zeolite also controls the formation of unwanted products via molecular sieving effect and hence ensuring the formation of acylation product with high selectivity. 
The XRD patterns of the synthesized LTL zeolites are shown in Fig. 2, matching well with the standard LTL zeolite with no impurities [31]. Furthermore, the XRD peaks intensity for all samples is high indicating low degree of structural collapse upon ion-exchange process. Also, no peaks shifting is observed demonstrating that the micropore size of the samples remains intact. Among these zeolite samples, only nanosized LTL zeolite exhibits broad XRD characteristic peaks due to its small crystallite size [32].

The morphological properties of the synthesized LTL zeolites were investigated using FESEM and the average dimensions of the zeolite crystals were calculated (Fig. 3, Table 2). As can be seen, the zeolites exhibit different morphologies and sizes. By using a precursor solution with high water content $\left(\mathrm{H}_{2} \mathrm{O} / \mathrm{Al}_{2} \mathrm{O}_{3}=1100\right)$, stick-like LTL zeolite with the longest rod length (ca. $6.03 \mu \mathrm{m}$ ) is prepared. In contrast, nanosized LTL zeolite with the shortest rod length (ca. $0.22 \mu \mathrm{m}$ ) is crystallized when the $\mathrm{H}_{2} \mathrm{O} / \mathrm{Al}_{2} \mathrm{O}_{3}=400$ is used. The morphological properties of the samples are further characterized by calculating their aspect ratios by dividing the length with the diameter of the crystals. It can be seen that nanosized LTL zeolite has the highest aspect ratio (4.40) as compared to the stick-like (3.92), cylindrical (2.01) and short-rod (0.96) LTL zeolites. Thus, when the water content in the precursor solution increases, a precursor hydrogel with diluted nutrients and low alkalinity is produced. As a result, a low supersaturation solution with few nucleation sites is produced. This solution favours more in crystal growth, leading to the formation of LTL zeolite crystals with larger crystal size and higher aspect ratio [33].

The morphology of LTL zeolite also influences the number of 1D micropore channels in the zeolites. Hence, the number of micropore channels, $\mathrm{n}_{\mathrm{ch}}$, is calculated [34]. Cylindrical LTL zeolite contains the largest number of parallel micropore channels (1144068), followed by stick-like LTL (633217), short-rod LTL (493843) and nanosized LTL (668) zeolites. Hence, 
it is expected that those LTL zeolite samples will have different catalytic performance due to different diffusion path length which will be discussed in Section 3.2.1.

The IR spectra of the zeolite samples were also recorded. In general, all samples exhibit similar IR pattern as the theoretical LTL zeolite, indicating that the framework structure of LTL zeolite remains stable after ion exchange process which is in line with the XRD analysis (Fig. 4) [35]. The IR absorption band at around $3460 \mathrm{~cm}^{-1}$ corresponds to the O-H stretching vibration mode of water molecules. The bands in the range of 1162 to $1024 \mathrm{~cm}^{-1}$ are attributed to the asymmetrical stretching vibration modes of $\mathrm{Si}-\mathrm{O}-\mathrm{T}(\mathrm{T}=\mathrm{Si}$ or $\mathrm{Al})$ tetrahedral, while the bands at 771 and $727 \mathrm{~cm}^{-1}$ correspond to the internal and external symmetrical stretching of the tetrahedral groups, respectively [36]. Meanwhile, the main characteristic bands of doublesix-ring (D6R) vibrations for LTL zeolite are confirmed at 650, 611 and $583 \mathrm{~cm}^{-1}$ [36]. At far IR region, two bands observed at 476 and $435 \mathrm{~cm}^{-1}$ are ascribed to the T-O bending mode of $\mathrm{TO}_{4}$ and the pore opening vibrations for external linkage, respectively [35].

The structural stability is further confirmed by the TG/DTG analysis. As shown, all samples exhibit two steps of weight loss (Fig. 5). The first stage of weight loss below $170{ }^{\circ} \mathrm{C}$ is due to the desorption of physisorbed water. The second stage of weight loss from $170{ }^{\circ} \mathrm{C}$ until $320{ }^{\circ} \mathrm{C}$ is attributed to the desorption of chemisorbed water [37]. As seen, the degree of weight loss is different in every samples due to different pore properties (e.g. surface areas and pore volumes).

The effects of morphology on porous properties of LTL zeolites were further examined using nitrogen adsorption-desorption measurement. All the samples display typical type I adsorption isotherms with significant nitrogen uptake at low $\mathrm{P} / \mathrm{P}_{\mathrm{o}}$ (Fig. 6) [38]. Interestingly, high nitrogen uptake at high $\mathrm{P} / \mathrm{P}_{\mathrm{o}}$ is also observed by nanosized LTL zeolite due to the presence of substantial textural meso- and macroporosities originated from their agglomeration (inset of Fig. 4) $[39,40]$. The surface areas $\left(\mathrm{S}_{\mathrm{BET}}, \mathrm{S}_{\mathrm{micro}}, \mathrm{S}_{\mathrm{ext}}\right)$ and total pore volume $\left(\mathrm{V}_{\text {Total }}\right)$ are also 
computed from the nitrogen adsorption data and the results are tabulated in Table 2. All the samples possess almost similar total surface area $\left(373-390 \mathrm{~m}^{2} / \mathrm{g}\right)$ where nanosized LTL zeolite has the highest external surface area $\left(97 \mathrm{~m}^{2} / \mathrm{g}\right)$ while cylindrical and stick-like LTL zeolites display the lowest external surface area (ca. $30 \mathrm{~m}^{2} / \mathrm{g}$ ). Nanosized LTL zeolite also exhibited lower micropore volume and lower crystallinity than the other three micron-sized counterparts which can be explained by the less perfect crystallization of the zeolite that contributes to the poor order of the three-dimensional network in the zeolite particles [41, 42]. The framework composition ( $\mathrm{Si} / \mathrm{Al}$ ratio) of LTL zeolites was analyzed by ICP-OES spectroscopy (Table 2). In general, the $\mathrm{Si} / \mathrm{Al}$ ratio of the molecular sieves is lower than those of the initial synthesis hydrogels. Nevertheless, the synthesized zeolites have almost similar aluminum content with a $\mathrm{Si} / \mathrm{Al}$ ratio ranging from 3.9-4.2. Hence, the morphological change has negligible influence on the structural composition of LTL zeolite framework.

The surface acidity of LTL zeolites is associated to the Al content and the micropore channels present in the solids. Hence, pyridine adsorption coupled with FTIR spectroscopy is used to study the acidity of zeolite samples where pyridine probe molecules interacted with the surface $\mathrm{Al}$ sites are measured as a scale of acidity $[43,44]$. The amount and the type of acid sites after pyridine desorption at 25,150 and $300^{\circ} \mathrm{C}$ are summarized in Table 3 . In general, the analysis shows the presence of Brönsted and Lewis acid sites in all samples by which these sites are characterized by the IR bands at $1544 \mathrm{~cm}^{-1}$ and $1452 \mathrm{~cm}^{-1}$, respectively. Nevertheless, the solids possess different amounts of acid sites with different acid strengths. For instance, cylindrical and stick-like LTL zeolites have larger total number acid sites $(L+B)$ than shortrod and nanosized LTL zeolites where it can be explained by their larger number of parallel micropore channels as compared to the other two samples that provides more diffusion accessibility. In addition, cylindrical and stick-like LTL zeolite crystals have longer morphological feature, which gives pronounced supramolecular confinement effect and 
enhances the strength of acid sites present in the micropores. In contrast, nanosized and shortrod LTL zeolites experience less supramolecular confinement effect due to their lower micropore surface area and higher external surface area, and hence the strength of their acid sites is lower.

The ratio of Brönsted acid to Lewis acid concentrations $(\mathrm{B} / \mathrm{L})$ of all samples was also calculated. The results indicate that the $\mathrm{B} / \mathrm{L}$ ratio increases with the aspect ratio of the micronsized zeolites. For instance, an increase in the $\mathrm{B} / \mathrm{L}$ ratio (e.g. at $300{ }^{\circ} \mathrm{C}$ ) from 0.82 to 1.35 is observed when the aspect ratio is increased from 0.96 to 3.92. Thus, this reveals that the needle and cylindrical LTL zeolites with longer crystal size have more Brönsted acid sites than shortrod LTL zeolite due to their long crystal shape that contains large number of parallel micropore channels and framework Al Brönsted acid sites [45]. For nanosized LTL zeolite, its B/L ratio is much lower than those micron-sized LTL zeolites because it has more Lewis acid sites originating from the defect sites (extra-framework Al) [46].

The acidity of LTL zeolites was also characterized with TPD- $\mathrm{NH}_{3}$ analysis where two signals are observed for all samples (Fig. 8). The first signal ranging from $40{ }^{\circ} \mathrm{C}$ to $230{ }^{\circ} \mathrm{C}$ is due to weak-to-mild acid sites while the second signal detected from $230{ }^{\circ} \mathrm{C}$ to $600{ }^{\circ} \mathrm{C}$ is originated from mild-to-strong acid sites [47]. The TPD- $\mathrm{NH}_{3}$ data also reveals that cylindrical $(510 \mu \mathrm{mol} / \mathrm{g})$ and stick-like $(495 \mu \mathrm{mol} / \mathrm{g})$ LTL zeolites have almost comparable number of acid sites where the number of their acid sites is higher than those of the other two counterparts (short-rod LTL: $370 \mu \mathrm{mol} / \mathrm{g}$, nanosized LTL: $346 \mu \mathrm{mol} / \mathrm{g}$ ).

\subsection{Catalytic reaction study}

Acylation of 2-methylfuran with acetic anhydride under solvent-free condition is chosen as a model reaction to study the morphological effects on the catalytic performance of LTL zeolites. The catalytic reaction is conducted using a novel non-microwave instant heating 
method where it can effectively and rapidly heat up the reaction system mimicking the microwave heating system [48]. No conversion is observed when the reaction is performed at $160{ }^{\circ} \mathrm{C}$ after 40 min without catalyst. However, the conversion increases tremendously with $100 \%$ selective to 2-acetyl-5-methylfuran when LTL zeolites are employed as the catalysts (Fig. 8A-C). For instance, $97.2 \%$ of conversion is recorded when the reaction is catalyzed by nanosized LTL zeolite at $160{ }^{\circ} \mathrm{C}$ for $20 \mathrm{~min}$ (Fig. 8C(d)). On the other hand, LTL zeolites with larger crystal size gives lower conversion (82.7-93.4\%) at the same time period (Fig. 7C(ac)). Among these three catalysts, stick-like LTL zeolite shows the best performance (93.4\%) in catalyzing acylation of 2-methyfuran, followed by cylindrical LTL zeolite $(89.8 \%)$ even though the latter one had slightly higher number of acidity. For short-rod zeolite sample, only $82.7 \%$ of conversion was achieved. Besides Brönsted acid sites, Lewis acid sites originated from the extraframework $\mathrm{Al}$ are also important in the acylation of 2-methylfuran as they cleave acetic anhydride into acetoxy anion, an activated intermediate prior the formation of 2-acetyl5-methylfuran [10].

\subsubsection{Reaction temperature dependence and activation energy}

The temperature dependence on the catalytic behaviour of LTL zeolites is studied in the range of $140-160{ }^{\circ} \mathrm{C}$ and the catalytic profile is monitored for $40 \mathrm{~min}$. In general, the reaction follows a normal sigmoidal curve where the conversion increases exponentially with time and becomes plateau at 90-95\% after $20 \mathrm{~min}$. The sigmoidal kinetic profile becomes more pronounced when the temperature increases (Fig. 8C). From the reaction study, a second-order kinetic is observed indicating the direct participation of both 2-methyfuran and acetic anhydride in the catalytic acylation reaction. 
The activation energies $\left(\mathrm{E}_{\mathrm{a}}\right)$ are calculated from the Arrhenius equation in order to further understand the morphological effects on the reaction kinetics. In the absence of catalyst, the $\mathrm{E}_{\mathrm{a}}$ of the reaction is $181.34 \mathrm{~kJ} / \mathrm{mol}$. However, the $\mathrm{E}_{\mathrm{a}}$ decreases when LTL zeolites are introduced. Nanosized LTL zeolite with high accessible acid sites (located at the external surface) has the lowest $\mathrm{E}_{\mathrm{a}}(106.83 \mathrm{~kJ} / \mathrm{mol})$, while cylindrical and stick-like LTL zeolites with large number of parallel micropore channels have slightly higher $\mathrm{E}_{\mathrm{a}}(108.20$ and $108.35 \mathrm{~kJ} / \mathrm{mol}$, respectively). On the other hand, the short-rod LTL zeolite with the lowest aspect ratio, low number of parallel micropore channels and weaker acid sites (both Brönsted and Lewis) are the least catalytically active, having the highest $E_{a}$ of $127.01 \mathrm{~kJ} / \mathrm{mol}$. Hence, this indicates that Friedel-Crafts acylation reaction is an activated catalytic reaction where LTL zeolites provide an alternative reaction pathway that has lower activation energy.

LTL zeolite is constructed strictly by a bunch of parallel one-dimensional (1D) channels where the number of channels of LTL zeolites is changed upon changing their morphology. Hence besides acidity, the aspect ratio is expected to influence the catalytic performance of the zeolites where it can also be presented in term of number of micropore channels, $\mathrm{n}_{\mathrm{ch}}$ [49]. Among micron-sized LTL zeolite samples, the best catalytic reaction performance is demonstrated by the stick-like LTL zeolite and it can be correlated with its large number of parallel micropore channels (633217) which help in facilitating reactants to diffuse into the micropore channels of LTL zeolite (Table 2). In addition, its longer crystal length $(6.03 \mu \mathrm{m}$ long) as compared to cylindrical zeolite LTL (4.16 $\mu \mathrm{m}$ long although cylindrical LTL zeolite has the largest number of parallel micropore channels (1144068)) is also found to significantly influence the catalytic acylation reaction where both 2-methylfuran and acetic anhydride can enter the LTL zeolite micropore channels from both ends without easily come out from micropores, diffuse deeper into the channels, adsorb on the Brönsted acid sites (from 
tetrahedral framework Al species) more effectively and react inside the channels when the reaction process proceeds.

In contrast, besides having lower amount of total acid sites $(B+L)$, short-rod LTL zeolites with shorter crystal length also tends to experience secondary diffusion effect where the reactants can easily go out when they diffuse into the micropores (micropore re-entry). As a result, the micropore diffusion length in short-rod LTL zeolite is much higher than those in cylindrical and stick-like LTL zeolites and indirectly decreasing its reaction activity.

For nanosized LTL zeolite, it has considerably low total number of acid sites with only 668 parallel micropore channels due to its reduced crystallite size. However, it shows the best catalytic performance as compared to the other three counterparts. Such phenomenon can be explained by its more accessible active sites which are located at the external surface area. As a result, the diffusion path length in nanozeolite is significantly reduced as compared to the that of micron-sized LTL zeolites thanks to its textural meso- and macroporosities. [50]. Based on these catalytic results, the best catalyst is nanosized LTL zeolite and the optimum reaction temperature and time are $160{ }^{\circ} \mathrm{C}$ and $20 \mathrm{~min}$, respectively.

\subsubsection{Catalyst comparative study}

Comparative catalytic performance between LTL zeolites and other catalysts is performed (Fig. 9). As can be seen, homogeneous acid catalysts such as $\mathrm{ZnCl}_{2}, \mathrm{H}_{2} \mathrm{SO}_{4}$ and $\mathrm{FeCl}_{3}$ give slightly higher reaction conversion $(98.8 \%, 98.4 \%$ and $97.9 \%$, respectively) than nanosized LTL zeolite $(97.2 \%)$ due to their strong acidity nature. However, these catalysts suffer from poor catalyst reusability and non-trivial separation. On the other hand, strong acid $\mathrm{HNO}_{3}(67 \mathrm{wt} \%$ or $14 \mathrm{M}$ ) only affords $56.4 \%$ conversion due to the presence of high water content in the concentrated acid while glacial acetic acid gives the lowest conversion $(39.4 \%)$ 
due to its weak acidity. The catalytic activity of nanosized LTL zeolite is also compared aluminum hydroxide fluoride $\left(\mathrm{AlF}_{2.9}(\mathrm{OH})_{0.1}\right)$ using similar reaction conditions [51]. It is shown that $\mathrm{AlF}_{2.9}(\mathrm{OH})_{0.1}$ gives the highest conversion (99.3\%) with only 2-acetyl-5-methylfuran produced, indicating that this Lewis catalyst is a more efficient catalyst than nanosized LTL zeolite for acylation reaction of 2-methylfuran. The catalytic performance comparison is also made with the closely related heterogeneous catalytic systems. Mesoporous H-AlMCM-41 catalyst (94.4\%) gives comparable conversion as nanosized LTL zeolite (97.2\%) albeit only one product is produced. For micron-sized H-Y zeolite, it shows lower catalytic activity than the nanosized LTL zeolite having $80.9 \%$ of conversion under the same reaction condition.

\subsubsection{Catalyst reusability study}

Catalyst reusability is a big challenge in liquid phase reactions particularly in biofuel production [52]. Therefore, a reusability study was performed for nanosized LTL zeolite at intermediate conversion level $(<50 \%)$ at $160{ }^{\circ} \mathrm{C}$ for $1 \mathrm{~min}[53]$ and the results are shown in Fig. 10. The reactivity of the recovered solid catalyst is preserved even after 10 consecutive reaction runs (average conversion 49.6\%) without any significant loss. Thus, nanosized LTL zeolite catalyst is fairly stable and hence it can be a recyclable solid acid catalyst for acylation of 2-methylfuran.

\section{Conclusion}

In conclusion, LTL zeolites synthesized from bamboo leaves ash (BLA) has been reported. The results show that the zeolite with different morphologies (short-rod, cylindrical, stick-like and nanosized shapes) and aspect ratios (0.96-4.40) can be obtained by simply tuning the water content in the precursor solutions. While the framework composition ( $\mathrm{Si} / \mathrm{Al}$ ratio) of 
samples is not affected to large extent upon changing the morphology, a significant change in the surface properties (surface areas, pore volume, pore size distribution) is observed for the solid samples. Furthermore, both the number and strength of acid sites (Brönsted and Lewis acids) of the solids are also changed when their morphology is altered. The LTL zeolite with cylindrical and stick-like shapes have stronger and larger number of Brönsted (B) and Lewis (L) acid sites than the short-rod and nanosized LTL zeolites. In addition, the B/L ratio also increases with the aspect ratio of the zeolites. Nanosized LTL zeolite appears to be the best solid acid catalyst in the acylation of 2 -methylfuran $\left(97.2 \%\right.$ conversion at $160{ }^{\circ} \mathrm{C}$ for $20 \mathrm{~min}$ ) thanks to its high accessible acid sites located at the external surface. In addition, high aspect ratio and large number of parallel micropore channels in the crystals are also found to have positive influence on the catalytic acylation reaction. Most importantly, the performance of nanosized LTL zeolite catalyst is maintained even after 10 consecutive reaction cycles, offering new eco-friendly process with a simple catalyst separation.

\section{Acknowledgement}

The financial support from FRGS (203/PKIMIA/6711642) is acknowledged.

\section{References}

[1] P. Abdeshahian, M. Dashti, M. Kalil, W. Yusoff, Biotechnol. 9 (2010) 274-282.

[2] J. He, L. Schill, S. Yang, A. Riisager, ACS Sustain. Chem. Eng. 6 (12) (2018) 1722017229

[3] B. Liu, Z. Zhang, ChemSusChem. 9 (2016) 1-23.

[4] P. Lanzafame, D. Temi, S. Perathoner, G. Centi, A. Macario, A. Aloise, Catal. Today 175 (2011) 435-441.

[5] D. Uraguchi, K. Sorimachi, M. Terada, J. Am. Chem. Soc. 126 (2004) 11804-11805.

[6] T.B. Poulsen, K.A. Jorgensen, Chem. Rev. 108 (2008) 2903-2915. 
[7] Y. Nakagawa, K. Tomishige, Catal. Commun. 12 (2010) 154-156.

[8] M. Balakrishnan, E.R. Sacia, A.T. Bell, Green Chem. 14 (2012) 1626-1635.

[9] W. Xu, H. Wang, X. Liu, J. Ren, Y. Wang, G. Lu, Chem. Commun. 47 (2011) 39243926.

[10] M. Koehle, Z. Zhang, K.A. Goulas, S. Caratzoulas, D.G. Vlachos, R.F. Lobo, Appl. Catal. A: Gen. 564 (2018) 90-101.

[11] G. Sartori, R. Maggi, Chem. Rev. 106 (2006) 1077-1104.

[12] E.P. Ng, G.K. Lim, G.L. Khoo, K.H. Tan, B.S. Ooi, F. Adam, T.C. Ling, K.-L. Wong, Mater. Chem. Phys. 155 (2015) 30-35.

[13] S.F. Wong, K. Deekomwong, J. Wittayakun, T.C. Ling, O. Muraza, F. Adam, E.-P. Ng, Mater. Chem. Phys. 196 (2017) 295-301.

[14] H. A. Smail, M. Rehan, K.M. Shareef, Z. Ramli, A.S. Nizami, J. Gardy, Chem Eng. 3 (2019) 35 .

[15] M. Bejblova, D. Prochazkova, J. Cejka, Chem. Sus. Chem. 2 (2009) 486-499.

[16] J.C. Kim, K. Cho, S. Lee, R. Ryoo, Catalysis Today 243 (2015) 103-108.

[17] U.P. Tran, K.K. Le, N.T. Phan, ACS Catal. 1 (2011) 120-127.

[18] G.D. Yadav, S.R. More, Appl. Clay Sci. 53 (2011) 254-262.

[19] G.M. Ziarani, N. Lashgari, A. Badiei, J. Mol. Catal. A: Chem. 397 (2015) 166-191.

[20] F. Adam, J.N. Appaturi, E.P. Ng, J. Mol. Catal. A: Chem. 386 (2014) 42-48.

[21] B. Yilmaz, N. Trukhan, U. Muller, Chin. J. Catal. 33 (1) (2012) 3-10.

[22] Y. Xiong, W. Chen, A. Zeng, Res. Chem. Intermediat. 43 (2017) 1557-1574.

[23] A. Gumidyala, B. Wang, S. Crossley, Sci. Adv. 2 (2016) e1601072.

[24] M. Kovacevic, S. Agarwal, B.L. Mojet, J.G. van Ommen, L. Lefferts, Appl. Catal. A: Gen. 505 (2015) 354-364.

[25] Y.J. Huang, G.R. Qi, L.S. Chen, Appl. Catal. A: Gen. 240 (2003) 263-271.

[26] Y.J. Lee, J.S. Lee, K.B. Yoon, Micropor. Mesopor. Mater. 80 (2005) 237-246.

[27] K.-W. Kow, R. Yusoff, A.R. Abdul Aziz, E.C. Abdullah, J. Non-Cryst. Solid. 386 (2014) 76-84.

[28] M.Y. Choo, J.C. Juan, L.E. Oi, T.C. Ling, E.P. Ng, A.R. Noorsaadah, G. Centi, K.T. Lee, Catal. Sci. Technol. 9 (2019) 772-782. 
[29] Baerlocher, C.; McCusker, L. B.; Olson, D. H. Atlas of Zeolite Framework Types; Elsevier: Amsterdam, the Netherlands, 2007.

[30] The size of 2-methylfuran and acetic anhydride was estimated using HyperChem ${ }^{\text {TM }}$ Release 7.03 for Windows Molecular Modeling System, Hypercube,Inc. 2002.

[31] IZA-SC Database of Zeolite Structures. http://www.iza-structure.org/ databases/.

[32] E.P. Ng, S.S. Sekhon, S. Mintova, Chem. Commun. 0 (2009) 1661-1663.

[33] T.M.A. Ghrear, S. Rigolet, T.J. Daou, S. Mintova, T.C. Ling, S.H. Tan, E.-P. Ng, Micropor. Mesopor. Mater. 277 (2019) 78-83.

[34] H. Mass, A. Khatyr, G. Calzaferri, Micropor. Mesopor. Mater. 65 (2003) 233-242.

[35] W. Insuwan, K. Rangsriwatananon, Eng. J. 16 (2012) 1-12.

[36] C. Li, Z. Wu, in S.M. Auerbach, K.A. Carrado, P.K. Dutta, Handbook of Zeolite Science and Technology, New York: Marcel Dekker Inc., 2003, p. 423-513.

[37] L. Tosheva, E.-P. Ng, S. Mintova, M. Hölzl, T.H. Metzger, A.M. Doyle, Chem. Mater. 20 (2008) 5721-5726.

[38] K.-H. Tan, H. Awala, R.R. Mukti, K.-L. Wong, T.C. Ling, S. Mintova, E.-P. Ng, J. Taiwan Inst. Chem. Eng. 58 (2016) 565-571.

[39] H. Zheng, F. Gao, V. Valtchev, J. Mater. Chem. A, 4 (2016) 16756-16770.

[40] E.-P. Ng, D.T.-L. Ng, H. Awala, K.-L. Wong, S. Mintova, Mater. Lett. 132 (2014) 126129.

[41] M.A. Camblor, A. Corma, S. Valencia, Micropor. Mesopor. Mater. 25 (1998) 59-74.

[42] J.M. Nhut, L. Pesant, J.P. Tessonnier, G. Wine, J. Guille, P.H. Cuong, M.J. Ledoux, Appl. Catal. A 254 (2003) 345-363.

[43] W. Song, C. Zhao, J.A. Lercher, Chem. Eur. J. 19 (2013) 9833-9842.

[44] E.-P. Ng, H. Nur, K.-L. Wong, M.N.M. Muhid, H. Hamdan, Appl. Catal. A: Gen. 323 (2007) 58-65.

[45] P.A. Alaba, Y. Mumammad Sani, W.M. Wan Daud, Chin J. Catal. 36 (2015) 18461851.

[46] D. Verma, R. Insyani, Y.-W. Suh, S.M. Kim, S.K. Kim, J. Kim, Green Chem. 19 (2017) 1969-1982.

[47] A.M. Camiloti, S.L. Jahn, N.D. Velasco, L.F. Moura, D. Cardoso, Appl. Catal. A: Gen. 182 (1999) 107-113.

[48] Y.-W. Cheong, K.-L Wong, T.C. Ling, E.-P. Ng, Mater. Exp. 8 (2018) 463-468.

[49] H. Mass, A. Khatyr, G. Calzaferri, Micropor. Mesopor. Mater. 65 (2003) 233-242. 
[50] X. Qi, V. Vattpalli, K. Zhang, P. Bai, P.J. Dauenhauer, W. Fan, Langmuir 35 (2019) 12407-12417.

[51] F. Frouri, S. Celerier, P. Ayrault, F. Richard, Appl. Catal. B: Environmental 168-169 (2015) 515-523.

[52] E.-P. Ng, J.-Y. Goh, T.C. Ling, R.R. Mukti, Nanoscale Res. Lett. 8 (2013) 120.

[53] F. Schüth, M.D. Ward, J.M. Buriak, Chem. Mater. 30 (2018) 3599-3600.

\section{$\underline{\text { Graphical abstract }}$}

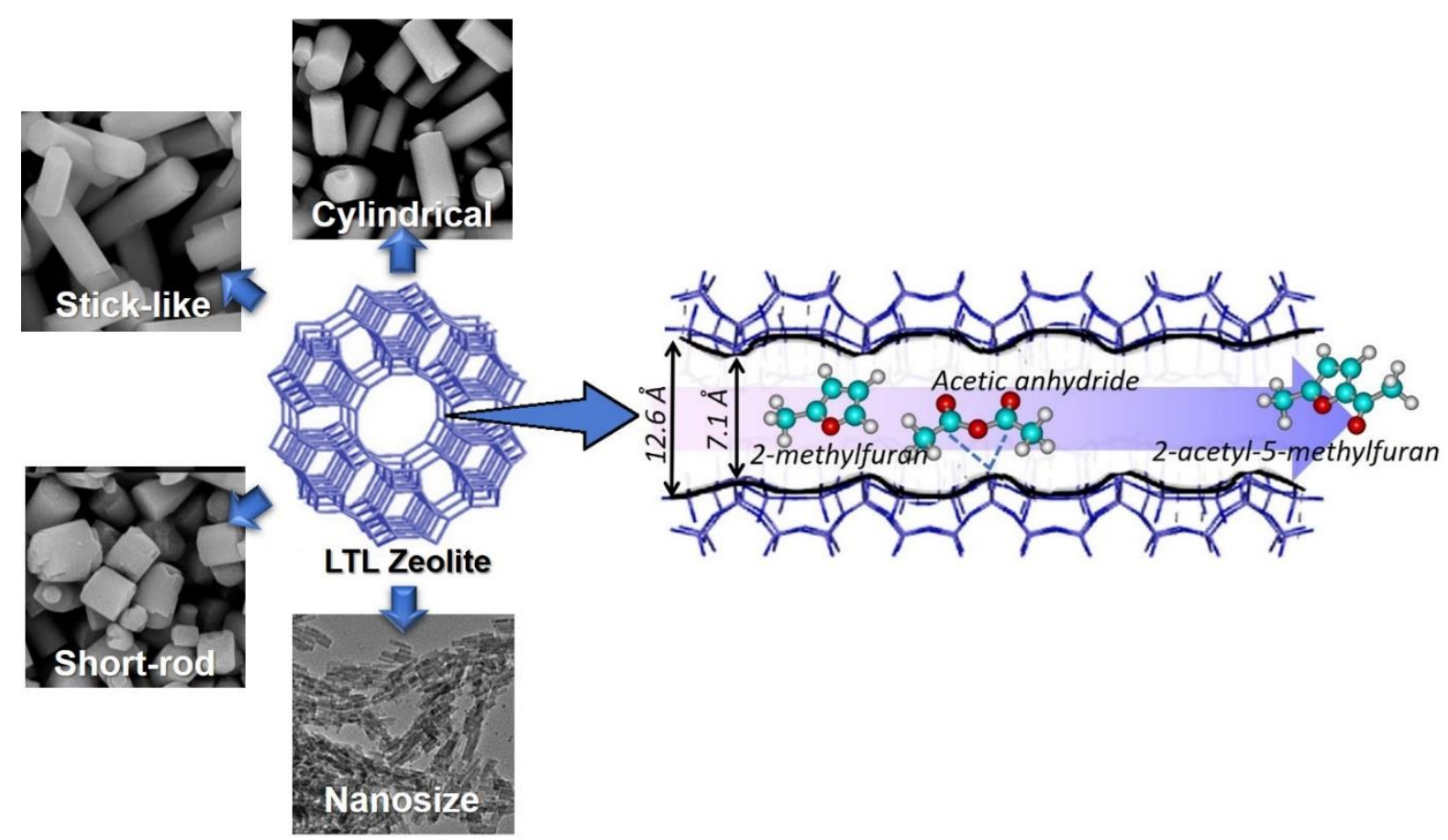

\section{$\underline{\text { Research highlights }}$}

- LTL zeolites with various morphologies are prepared using bamboo leaf ash silica.

- The morphological properties influence zeolite surface properties and acidity.

- Nanosized LTL zeolite has the best catalytic performance in acylation of 2-methylfuran.

- LTL nanozeolite shows better performance than common liquid and solid catalysts. 


\section{$\underline{\text { Figure captions }}$}

Fig. 1. (a) View of LTL zeolite framework along [001] plane showing its hexagonal structure; (b) schematic illustration of diffusion of reactants (2-methylfuran and acetic anhydride) and product (2-acetyl-5-methylfuran) in the LTL channel with a van der Waals opening of $7.1 \AA$ and a maximum internal pore diameter of $1.26 \AA$.

Fig. 2. XRD patterns of (a) theoretical, (b) cylindrical, (c) stick-like, (d) short-rod and (e) nanosized LTL zeolites.

Fig. 3. SEM images of (a) cylindrical, (b) stick-like and (c) short-rod LTL zeolites, and (d) TEM image of nanosized LTL zeolite.

Fig. 4. IR spectra of (a) cylindrical, (b) stick-like, (c) short-rod and (d) nanosized LTL zeolites.

Fig. 5. (A) TGA and (B) DTG plots of (a) cylindrical, (b) stick-like, (c) short-rod and (d) nanosized LTL zeolites.

Fig. 6. Nitrogen gas adsorption-desorption isotherms of (a) cylindrical, (b) stick-like, (c) shortrod and (d) nanosized LTL zeolites. Inset: Pore size distributions derived from DFT model.

Fig. 7. TPD-NH 3 curves of (a) cylindrical, (b) stick-like, (c) short-rod and (d) nanosized LTL zeolites.

Fig. 8. Effect of temperature and time on the conversion at (A) $140{ }^{\circ} \mathrm{C}$, (B) $150{ }^{\circ} \mathrm{C}$ and (C) 160 ${ }^{\circ} \mathrm{C}$ for (a) cylindrical, (b) stick-like, (c) short-rod and (d) nanosized LTL zeolites. (D) The Arrhenius plots of the LTL zeolite catalysts. Catalyst $=0.30 \mathrm{~g}, 2$-methylfuran $=4.7 \mathrm{mmol}$, acetic anhydride $=14.1 \mathrm{mmol}$, solvent-free. 
Fig. 9. Conversion of 2-methylfuran versus types of catalysts. Reaction conditions: temperature $=160{ }^{\circ} \mathrm{C}$, time $=20 \mathrm{~min}, 2$-methylfuran $=4.7 \mathrm{mmol}$, acetic anhydride $=14.1 \mathrm{mmol}$, catalyst $=$ $0.30 \mathrm{~g}$ (or equivalent to $0.1148 \mathrm{mmol}$ ), solvent-free.

Fig. 10. Reusability test of nanosized zeolite LTL. Reaction conditions: temperature $=160{ }^{\circ} \mathrm{C}$, time $=1 \mathrm{~min}, 2$-methylfuran $=4.7 \mathrm{mmol}$, acetic anhydride $=14.1 \mathrm{mmol}$, catalyst $=0.30 \mathrm{~g}$ of nanosized LTL zeolite equivalent to $0.1148 \mathrm{mmol}$ of liquid or solid catalyst, solvent-free.

\section{$\underline{\text { Figures }}$}

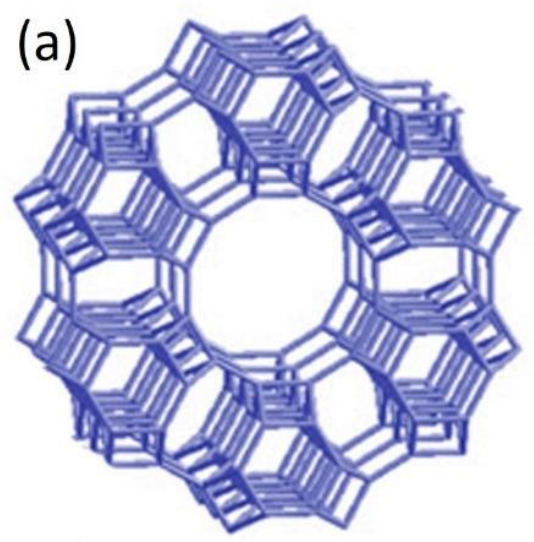

(b)

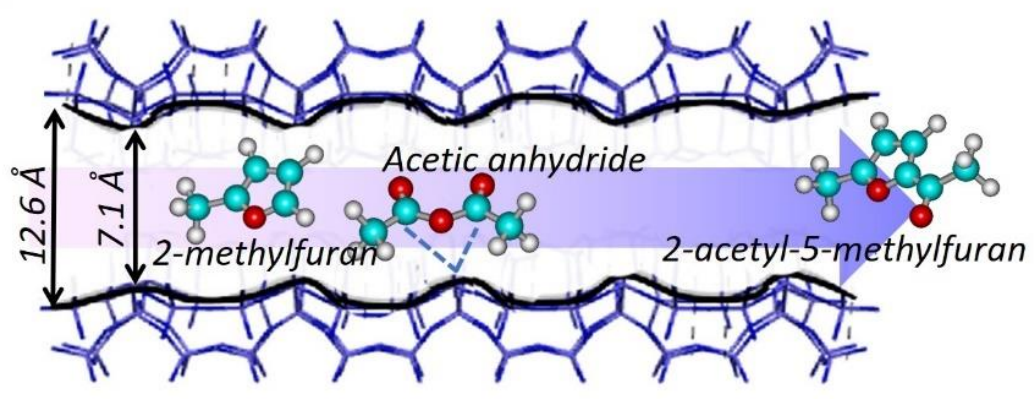

Fig. 1. 


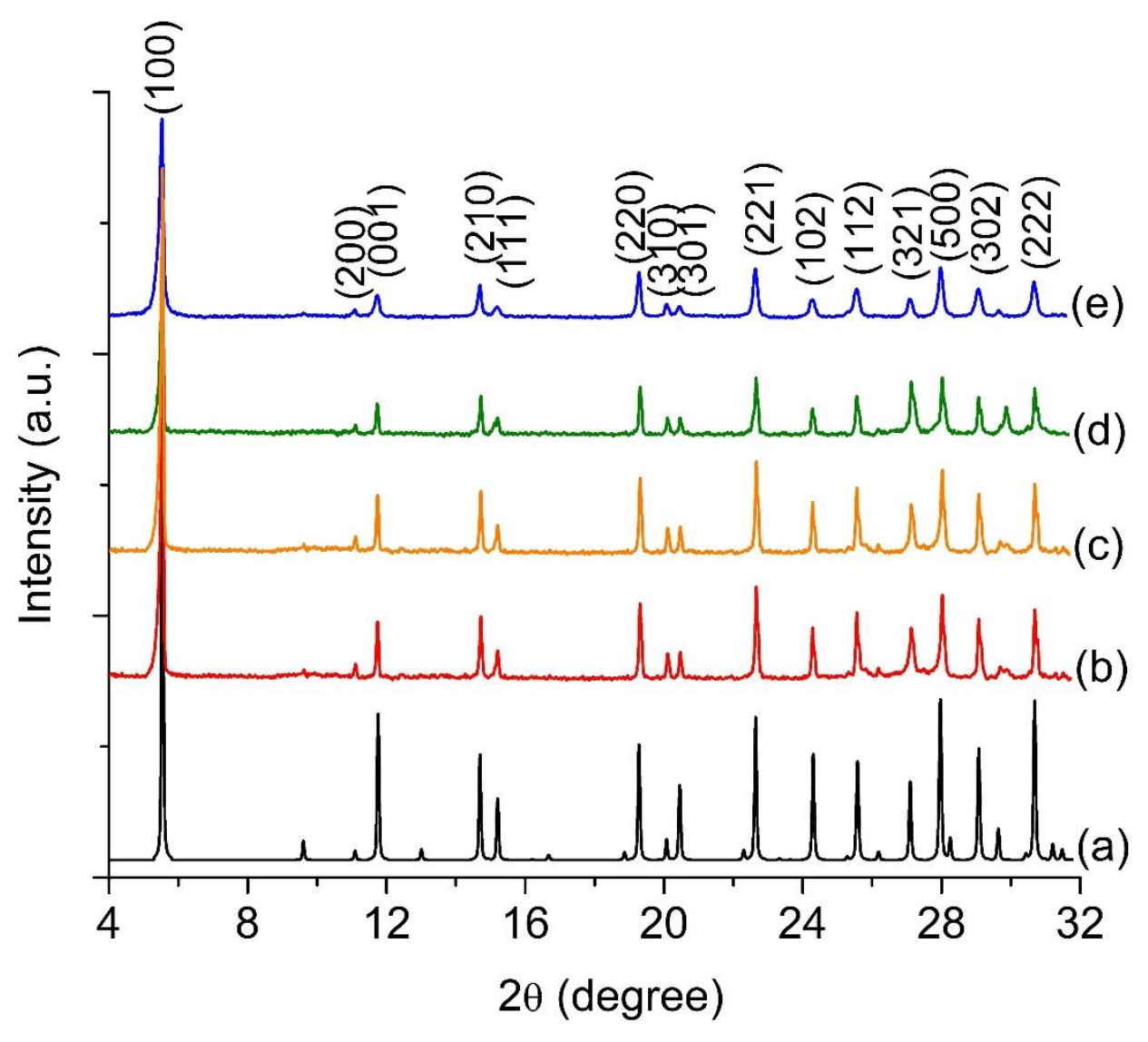

Fig. 2 


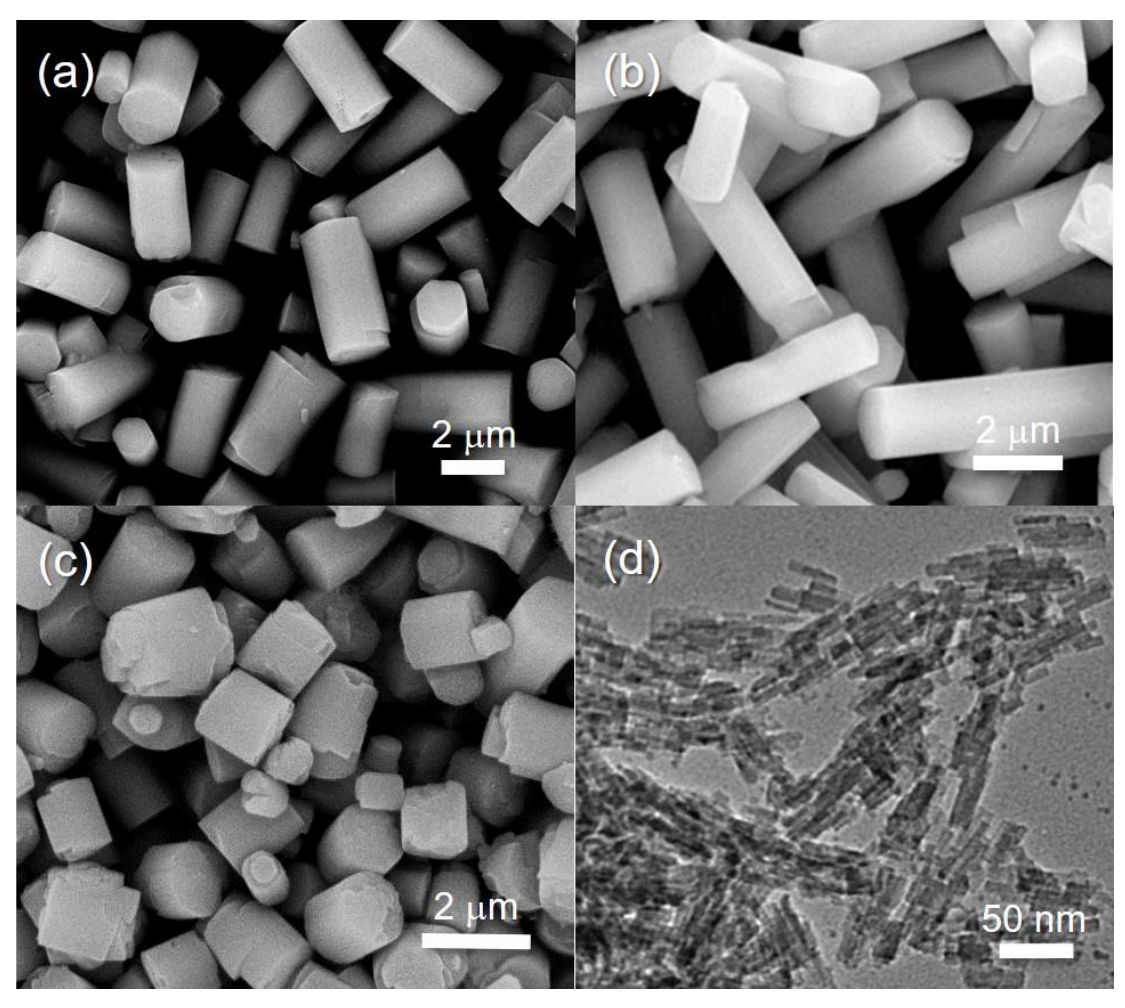

Fig. 3 


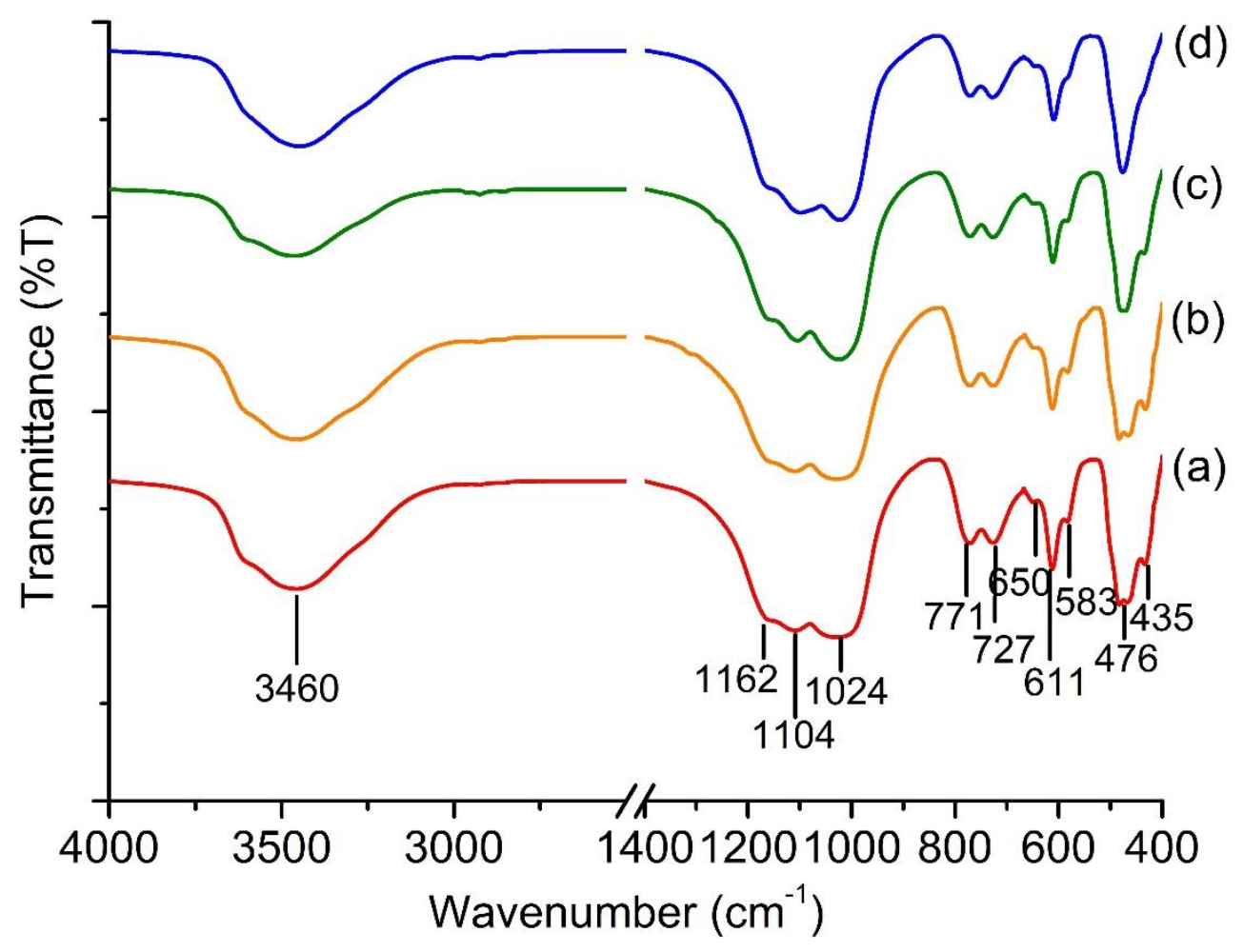

Fig. 4 

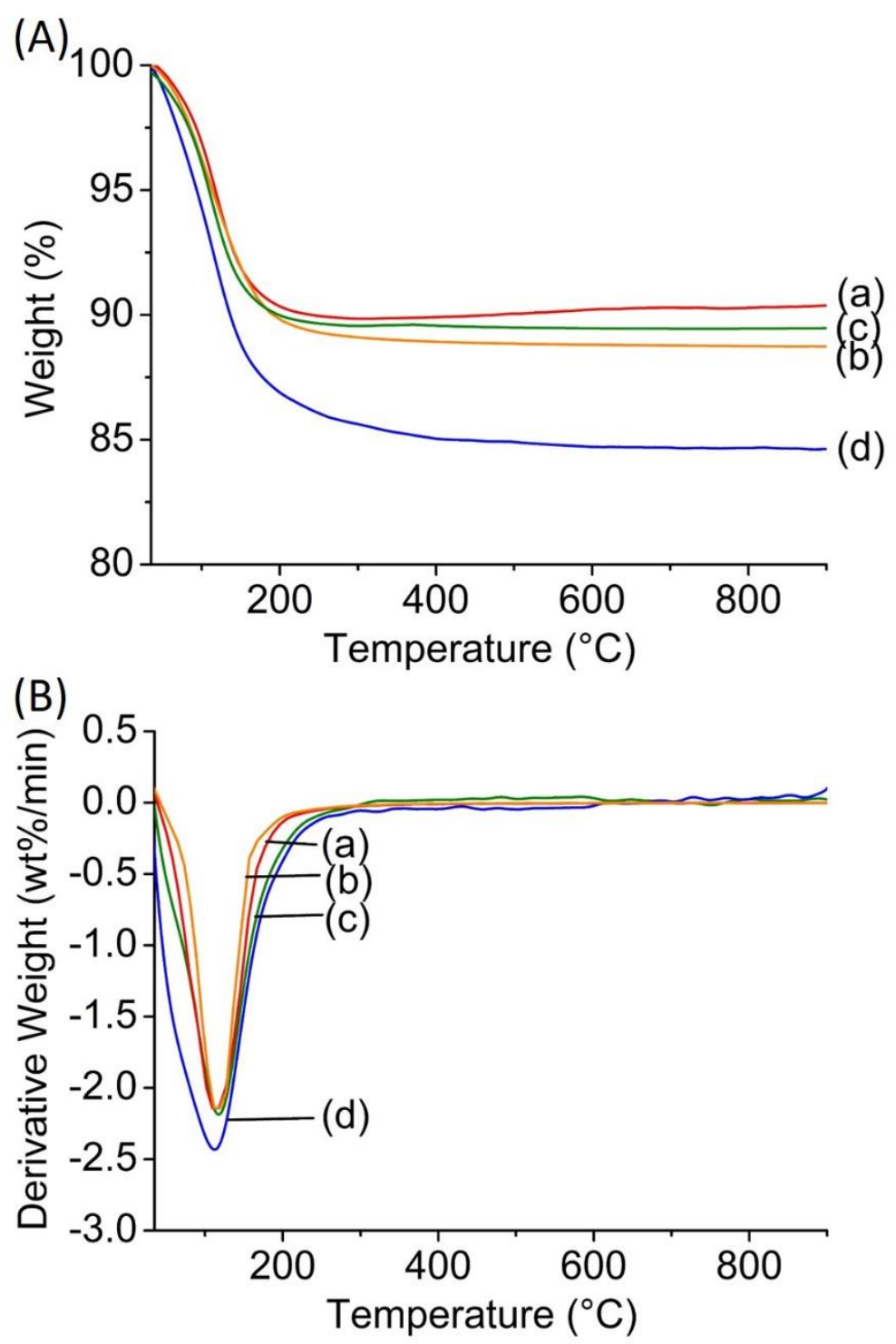

Fig. 5 


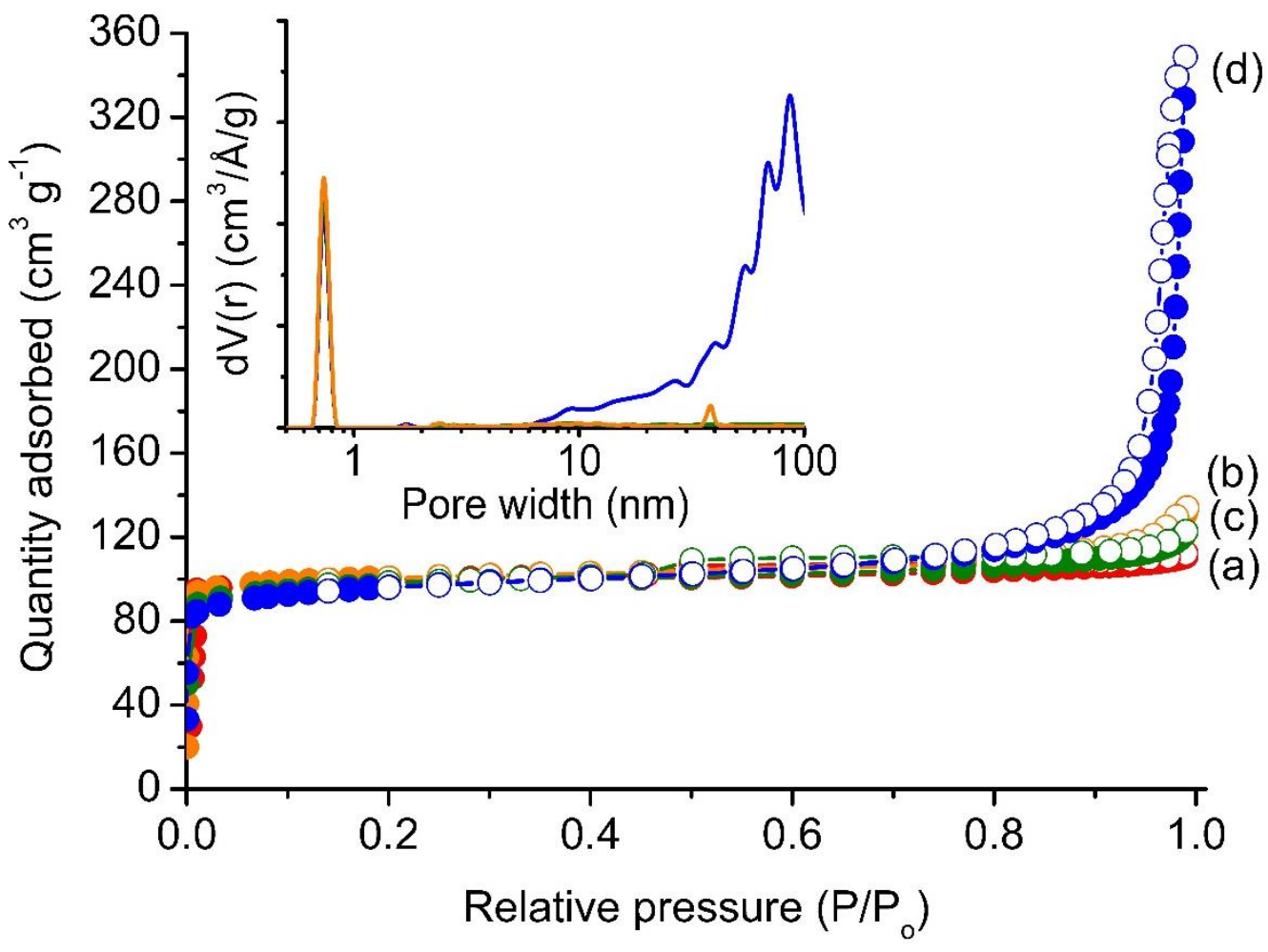

Fig. 6 


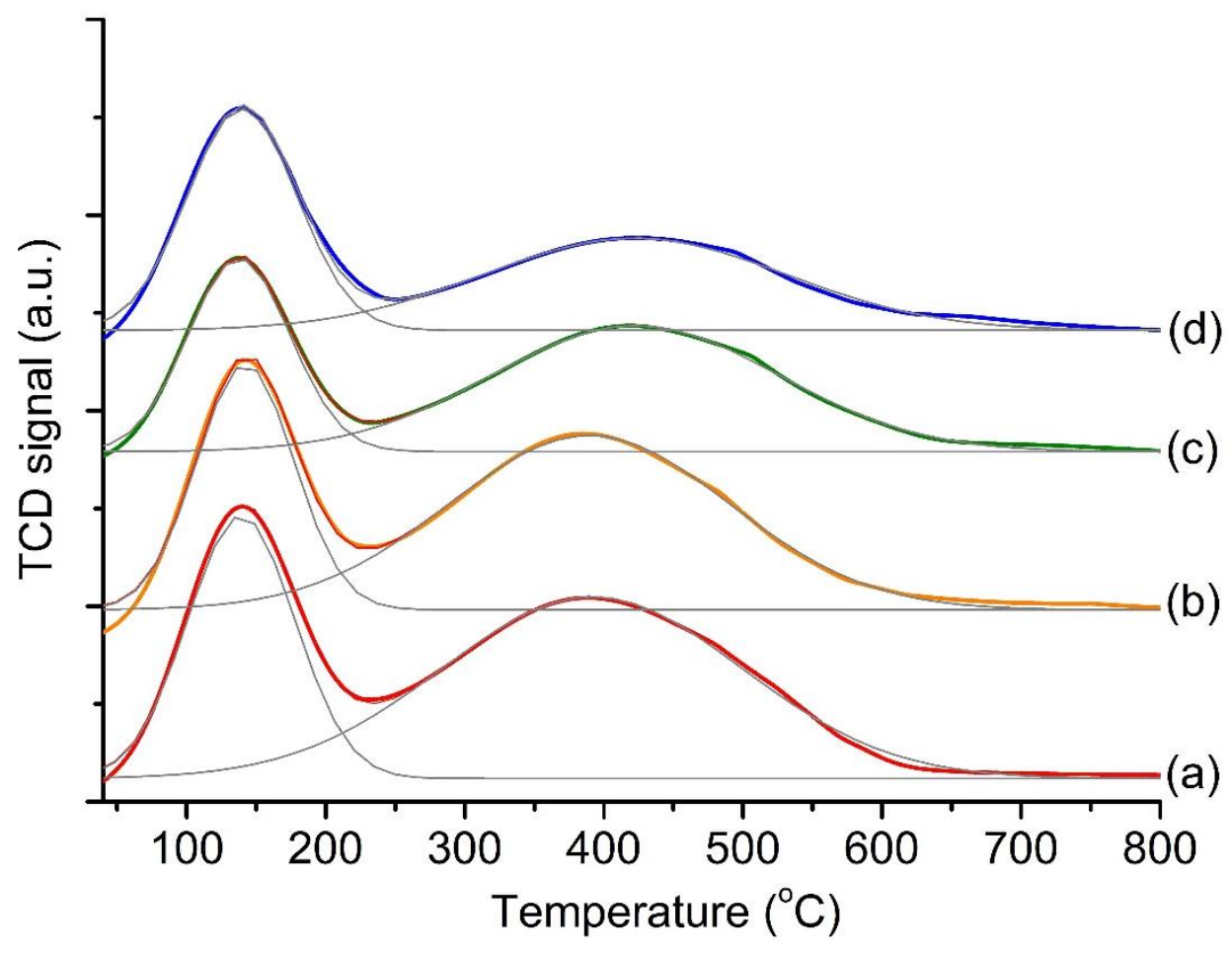

Fig. 7 

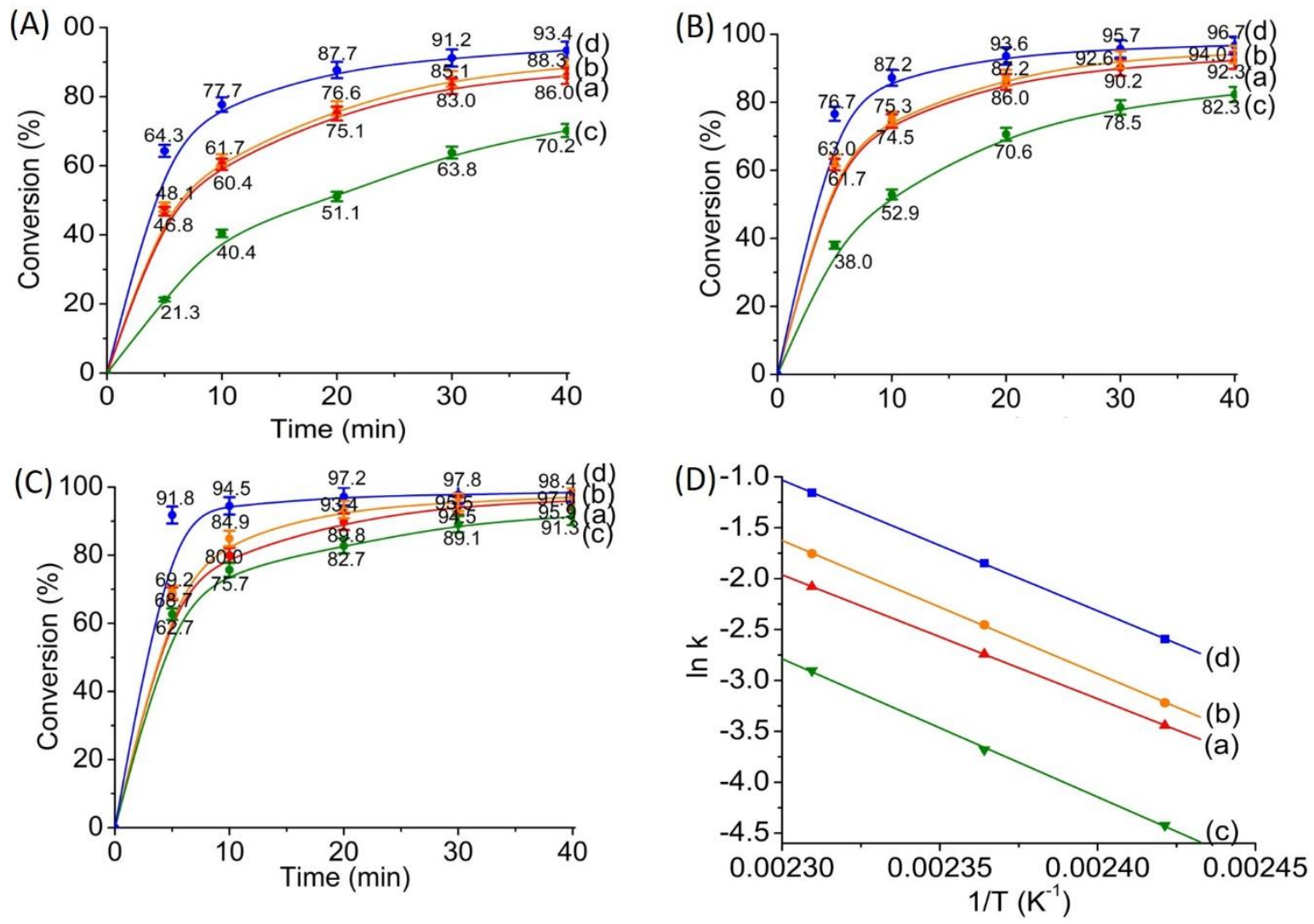

Fig. 8 


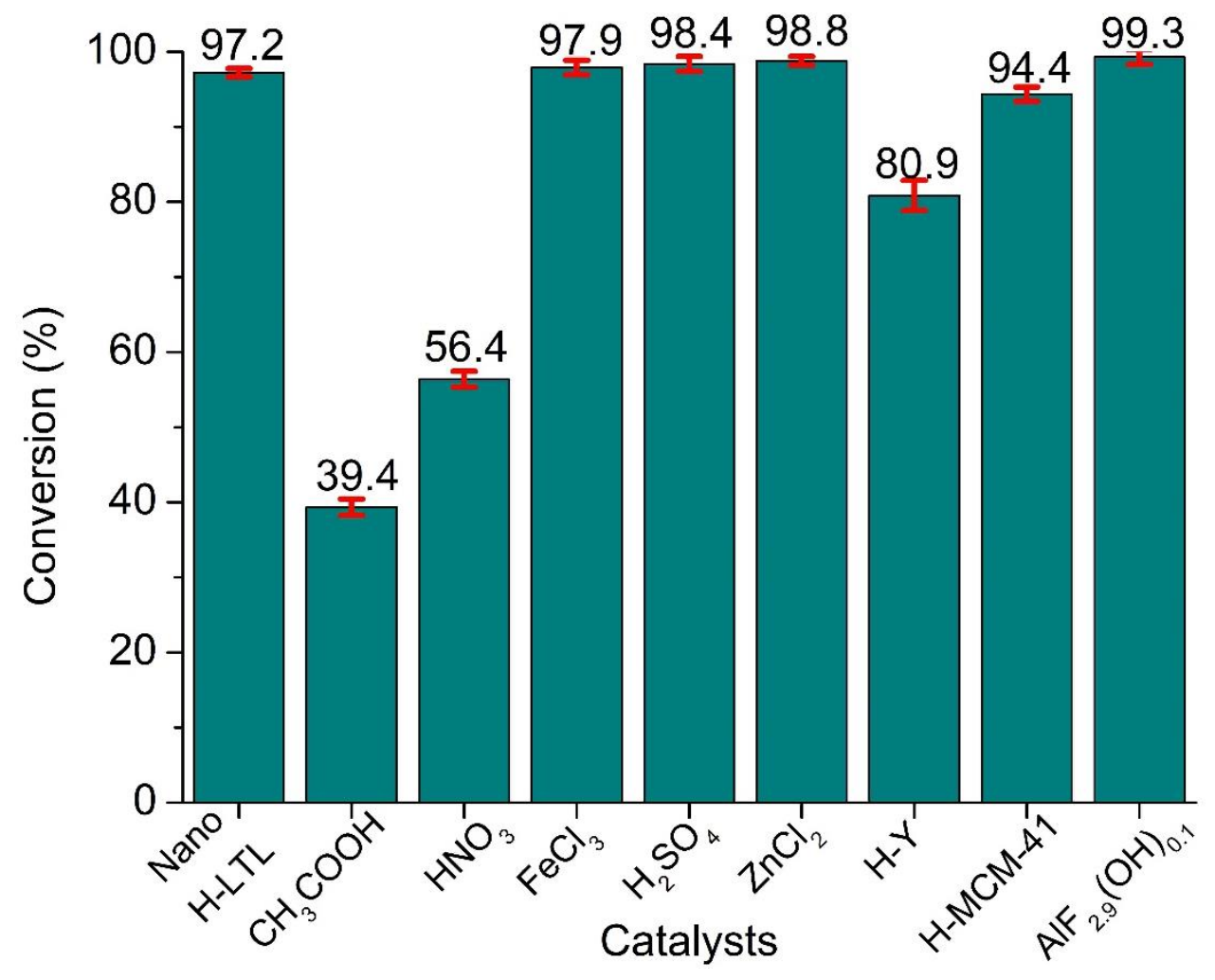

Fig. 9 


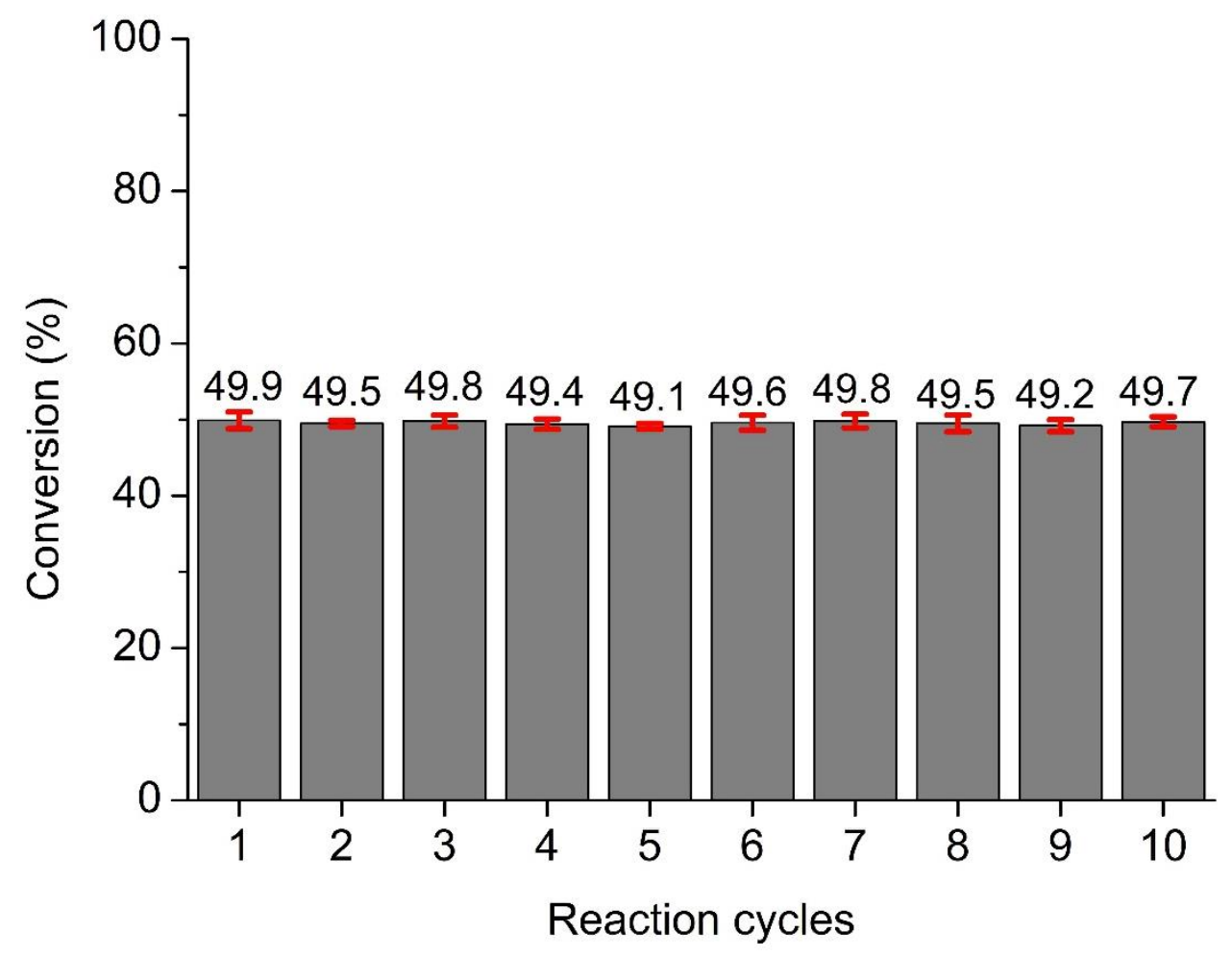

Fig. 10

$\underline{\text { Tables }}$

Table 1. Molar compositions of hydrogels and the synthesis conditions for the preparation of LTL zeolites.

\begin{tabular}{cccccccc}
\hline \multirow{2}{*}{ Samples } & \multicolumn{3}{c}{ Molar composition } & & Aging & Temperature & Time \\
\cline { 2 - 5 } & $\mathbf{A l}_{\mathbf{2}} \mathbf{O}_{\mathbf{3}}$ & $\mathbf{S i O}_{2}$ & $\mathbf{K}_{\mathbf{2}} \mathbf{O}$ & $\mathbf{H}_{\mathbf{2}} \mathbf{O}$ & $(\mathbf{h})$ & $\left({ }^{\mathbf{o}} \mathbf{C}\right)$ & $(\mathbf{h})$ \\
\hline Nanosized LTL & 1 & 20 & 10 & 400 & 24 & 180 & 5 \\
Short-rod LTL & 1 & 20 & 10 & 800 & 18 & 180 & 72 \\
Stick-like LTL & 1 & 20 & 10 & 1100 & 18 & 180 & 72 \\
Cylindrical LTL & 1 & 20 & 10 & 1030 & 18 & 180 & 72 \\
\hline
\end{tabular}


Table 2. Chemical compositions, surface and textural properties of LTL zeolites.

\begin{tabular}{lcccc}
\hline & $\begin{array}{c}\text { Cylindrical } \\
\text { LTL }\end{array}$ & $\begin{array}{c}\text { Stick-like } \\
\text { LTL }\end{array}$ & $\begin{array}{c}\text { Short-rod } \\
\text { LTL }\end{array}$ & $\begin{array}{c}\text { Nanosized } \\
\text { LTL }\end{array}$ \\
\hline Chemical composition & 4.1 & 4.1 & 3.9 & 4.2 \\
\hline Si/Al ratio & 375 & 390 & 373 & 387 \\
$\frac{\text { Porosity }}{\mathrm{S}_{\mathrm{BET}}\left(\mathrm{m}^{2} / \mathrm{g}\right)}$ & 345 & 362 & 330 & 290 \\
$\mathrm{~S}_{\text {micro }}\left(\mathrm{m}^{2} / \mathrm{g}\right)$ & 30 & 28 & 43 & 97 \\
$\mathrm{~S}_{\text {ext }}\left(\mathrm{m}^{2} / \mathrm{g}\right)$ & 0.18 & 0.20 & 0.19 & 0.54 \\
$\mathrm{~V}_{\text {total }}\left(\mathrm{cm}^{3} / \mathrm{g}\right)$ & & & & \\
Textural properties & $2.07 \pm 0.10$ & $1.54 \pm 0.21$ & $1.36 \pm 0.07$ & $0.05 \pm 0.01$ \\
\hline Width $(\mu \mathrm{m})$ & $4.16 \pm 0.15$ & $6.03 \pm 0.48$ & $1.30 \pm 0.40$ & $0.22 \pm 0.02$ \\
Length $(\mu \mathrm{m})$ & 2.01 & 3.92 & 0.96 & 4.40 \\
Aspect ratio & 1144068 & 633217 & 493843 & 668 \\
$\mathrm{n}_{\mathrm{ch}}{ }^{\mathrm{a}}$ & & & & \\
\hline
\end{tabular}

${ }^{\mathrm{a} N u m b e r}$ of parallel channels $=0.267\left(\mathrm{~d}_{\mathrm{z}}\right)^{2}$ where $\mathrm{d}$ 的 the average diameter of zeolite crystals in $\mathrm{nm}[49]$. 
Table 3. Characterization of surface acidity of zeolites LTL with various morphologies.

\begin{tabular}{|c|c|c|c|c|c|c|c|c|c|c|c|c|c|c|c|}
\hline \multirow{3}{*}{ Samples } & \multicolumn{12}{|c|}{ Py-FTIR acidity $(\mu \mathrm{mol} / \mathrm{g})$} & \multicolumn{3}{|c|}{ TPD-NH 3 acidity $(\mu \mathrm{mol} / \mathrm{g})$} \\
\hline & \multicolumn{3}{|c|}{ Lewis acid sites (L) } & \multicolumn{3}{|c|}{ Brönsted acid sites (B) } & \multicolumn{3}{|c|}{ Total acid sites $(\mathrm{L}+\mathrm{B})$} & \multicolumn{3}{|c|}{$\mathrm{B} / \mathrm{L}$ ratio } & \multirow{2}{*}{$\begin{array}{l}\text { Weak-to- } \\
\text { mild }\end{array}$} & \multirow{2}{*}{$\begin{array}{l}\text { Mild-to- } \\
\text { strong }\end{array}$} & \multirow{2}{*}{ Total } \\
\hline & $25^{\circ} \mathrm{C}$ & $150^{\circ} \mathrm{C}$ & $300^{\circ} \mathrm{C}$ & $25^{\circ} \mathrm{C}$ & $150^{\circ} \mathrm{C}$ & $300^{\circ} \mathrm{C}$ & $25^{\circ} \mathrm{C}$ & $150^{\circ} \mathrm{C}$ & $300{ }^{\circ} \mathrm{C}$ & $25^{\circ} \mathrm{C}$ & $150^{\circ} \mathrm{C}$ & $300^{\circ} \mathrm{C}$ & & & \\
\hline Cylindrical & & & & & & & & & & & & & & & \\
\hline LTL & 236.6 & 145.0 & 36.9 & 212.9 & 175.8 & 147.3 & 449.4 & 320.9 & 236.6 & 0.9 & 1.2 & 4.0 & 160 & 350 & 510 \\
\hline Stick-like & & & & & & & & & & & & & & & \\
\hline LTL & 186.2 & 138.7 & 36.6 & 251.6 & 185.6 & 177.1 & 437.8 & 324.3 & 186.2 & 1.4 & 1.3 & 4.9 & 158 & 334 & 495 \\
\hline Short-rod & & & & & & & & & & & & & & & \\
\hline LTL & 233.3 & 103.2 & 28.1 & 192.4 & 116.3 & 97.1 & 425.7 & 219.4 & 233.3 & 0.8 & 1.1 & 3.4 & 129 & 241 & 370 \\
\hline Nanosized & & & & & & & & & & & & & & & \\
\hline LTL & 296.2 & 148.7 & 30.7 & 119.1 & 106.6 & 24.4 & 415.4 & 255.3 & 296.2 & 0.4 & 0.7 & 0.8 & 161 & 185 & 346 \\
\hline
\end{tabular}


